\title{
Automation of production programs by setting conditions of stabilization of the planned system
}

\author{
Alexey Yurgaytis*, Kamol Kamolov \\ Moscow State University of Civil Engineering, 129337, Moscow, Russia
}

\begin{abstract}
Formation of a production program is a time-consuming variable problem. To solve it, many conditions and constraints must be taken into account. Computer power allows one to quickly and accurately solve problems with many variables, unlike a person who relies on his intuition and experience. The following materials and methods were used: collection and analysis of data from construction companies of various sizes, mathematical modeling of the processes of distributing labor resources, graphic interpretation of information, computer modeling. The stages of the problem statement: description of the organizational and technological problem of distributing labor resources, mathematical formulation, modeling and algorithmization using well-known metaheuristic approaches. In the course of solving the problem, a genetic algorithm was used that allows one to quickly find solutions in equations with many variables. The following constraints were determined: deadlines, maximum and minimum number of workers at the facility, minimum number of transfer of resources, minimum involvement of a subcontractor. As a result, all the necessary mathematical models and initial data for the development of a computer program for the automated distribution of labor resources among the facilities of the production program of the construction and installation organization were obtained.
\end{abstract}

\section{Introduction}

One of the most important strategic areas for the prosperity of a construction company is the development of principles for organizing construction to ensure the order and conditions for the construction of facilities in order to put them into operation on time with high quality [2]. The main way of increasing labor efficiency is the automation and computerization of design, construction and installation works, the creation of computeraided design systems - CAD. CAD systems allow a person to use a computer in order to collect and process information through special devices and make decisions on construction issues based on a dialogue with a computer [1]. The level of automation of organizational

\footnotetext{
*Corresponding author: aljurgaitis@gmail.com
} 
work in Russia is gradually increasing, but not at the same rate as in Western Europe, China, and the United States, where the indicator of designers' investment has increased threefold compared to Russia [1,2].The planning and design phase takes up approximately $20 \%$ of the entire project life cycle.Therefore, the use of software is wise for accurate and fast calculations. In Russia, only large companies use automated management systems, and mainly for long-term planning. These systems are necessary not only for designers, but also for construction companies, who face organizational issues at the construction site on a daily basis. There are many systems with elements of artificial intelligence such as CAD, CAM, BIM, which significantly help the contractor in the work, but CAM lags far behind other systems.Even with perfect long-term planning, unforeseen situations arise, due to which the company cannot cope with current planning and loses its efficiency, and, consequently, money. Formation of the production program is the main component of the construction production organization system and is formed on the basis of the received order portfolios. Operational planning solves the following main tasks: rational use of production resources, implementation of construction and installation works in accordance with production schedules, ensuring continuity of work, timely provision of the spread of work for related construction work, rational distribution of labor resources by facilities $[6,7]$. Therefore, the main task of the computer is the calculation of the production program and further adjustments to the plan when new information is received, i.e. operational planning. The main indicator of the production program of a construction organization is production capacity $[3,4]$. The terminological definition of the concept of capacity has a certain trinity of physical interpretation. In the context of this paper, an organizational and technological interpretation will be used, expressing capacity through the providing labor resource. Thus, it becomes necessary to form computer algorithms to assess the initial capacity of a construction organization and its rational use during the implementation of the production program of a construction organization.

\section{Materials and methods}

The relevance of using computer technology is caused by a significant increase in the number of large companies, and, therefore, design and organizational work. Large construction companies have more than 500 full-time employees and more than 7 simultaneously operating facilities [23]. The use of modern methods of organizing work and the use of computer technology is necessary to process a large amount of information. At the same time, a spontaneous increase in the scope of work in project portfolios is recorded due to the specifics of market relations and the inexpediency of refusal of company leaders from any projects due to the need for permanent development of their own business $[8,9]$.

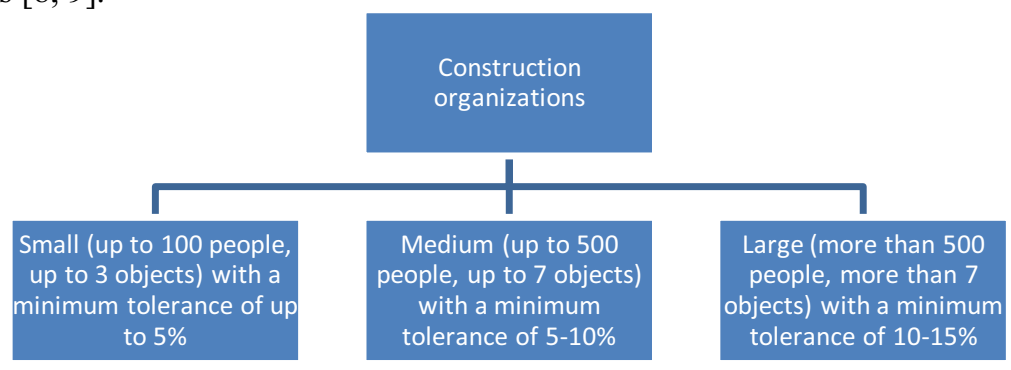

Fig. 1.Division of construction and installation organizations depending on the number of full-time production units, taking into account the permissible deviations from the planned indicators (noncritical fluctuation). 
It is intuitively clear that there are a significant number of options for the distribution of workers among the objects of the current period. The objective of the study is to develop an approach to automating and optimizing the distribution of labor resources in the modern era of digitalization for the implementation of this algorithm into a single information model $[10,11]$. To create a computer program, it is necessary to describe and mathematically substantiate the solution to the problem. The complexity of the development of a mathematical model, associated with a large number of conditions and constraints, requires some simplification in order to take into account and standardize all significant factors $[11,12]$.

Stages of creating an automated software package for the current regulation of the labor resource between the objects of the production program [13]:

1. Description of the logic of solving the organizational and technological problem of distribution

2. Mathematical formulation, modeling

3. Algorithmization using well-known metaheuristic approaches

Implementation of construction work using an integrated team can be carried out by a parallel, sequential and flow method. The method of planning work is more complicated in comparison with specialized teams $[14,15]$.

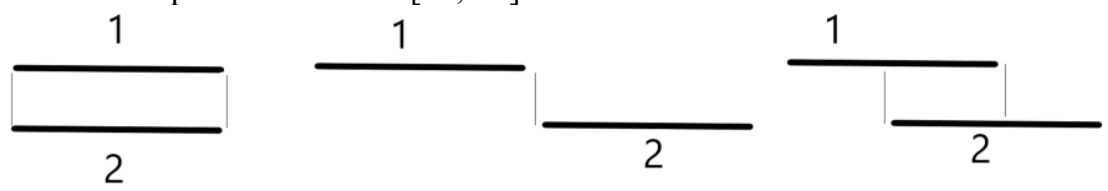

Fig. 2. Work organization options.

There are two ways to describe these options for organizing work:

1. By the duration of work (entering the start and end date of the process).

2. By the scope of work. A work combination coefficient is introduced, which determines what part of the work must be completed by the time the next work begins. $\mathrm{kp}=$ $\Delta / \mathrm{V} 1$, where $\Delta$ is the planned amount of work to be done before the next one; V1 planned labor intensity of 1 process. This assumption was described in the works of V.Ya. Mishchenko and D.I. Emelyanov [5].

The labor resource that can be provided to a construction company characterizes the production capacity of the organization $[16,17]$. Let's consider a company who only deals with monolithic work. R0 is the staff number of workers (people). The distribution of workers requires detailed information on their specialty and classification. Thus, we create a kind of workers database.

Option 1. With an unknown exact value of workers with more than one specialization.

Table 1. Workers database.

\begin{tabular}{|c|c|c|c|c|c|c|c|}
\hline \multicolumn{2}{|c|}{ R-number of persons } & \multicolumn{5}{|c|}{ Qualification } & \multirow[t]{2}{*}{$\mathrm{R}_{\text {sum }, \mathrm{i}}$} \\
\hline No. & Specialization & 2 & 3 & 4 & 5 & 6 & \\
\hline 1 & Mounter & $\mathrm{R}_{\mathrm{m} 2}$ & $\mathrm{R}_{\mathrm{m} 3}$ & $\mathrm{R}_{\mathrm{m} 4}$ & $\mathrm{R}_{\mathrm{m} 5}$ & $\mathrm{R}_{\mathrm{m} 6}$ & $\mathrm{R}_{\text {sum1 }}$ \\
\hline 2 & Steel fixer & $\mathrm{R}_{\mathrm{st} 2}$ & $\mathrm{R}_{\mathrm{st3}}$ & $\mathrm{R}_{\mathrm{st} 4}$ & $\mathrm{R}_{\mathrm{st5}}$ & $\mathrm{R}_{\mathrm{st} 6}$ & $\mathrm{R}_{\text {sum2 }}$ \\
\hline 3 & $\begin{array}{l}\text { Concrete } \\
\text { worker }\end{array}$ & $\mathrm{R}_{\text {con2 }}$ & $\mathrm{R}_{\text {con3 }}$ & $\mathrm{R}_{\text {con } 4}$ & $\mathrm{R}_{\text {con5 }}$ & $\mathrm{R}_{\text {con6 }}$ & $\mathrm{R}_{\text {sum3 }}$ \\
\hline 4 & Locksmith & $\mathrm{R}_{\mathrm{lsm} 2}$ & $\mathrm{R}_{\mathrm{lsm} 3}$ & $\mathrm{R}_{\mathrm{Ism} 4}$ & $\mathrm{R}_{1 \mathrm{sm} 5}$ & $\mathrm{R}_{\mathrm{lsm} 6}$ & $\mathrm{R}_{\text {sum4 }}$ \\
\hline
\end{tabular}

In this case, we introduce an additional coefficient of combination of professions $\mathrm{k}_{\mathrm{p}}$, which describes which part of the workers have additional qualifications. This value is either entered by the operator, or an approximate value $\mathrm{k}_{\mathrm{p}}=0.15$ is taken. This means that 
$15 \%$ of workers have two specializations. Therefore, Rimax $=$ Risum $+0.15 *\left(\mathrm{R}_{0}-\right.$ $\left.R_{\text {isum }}\right) /(n-1)$, where $R_{\text {isum }}$ - the total number of concrete workers, $R_{0}$ - the number of staff members, $n$ - the number of specializations. It should also be noted that $\sum R_{i}$ max should not exceed $\mathrm{R}_{0}$.

Option 2. When the exact value of workers with more than one specialization is known, an additional table "2nd degree" is introduced, where R' is the number of workers borrowed from other specializations.

Table 2. Database of workers of the "2nd degree".

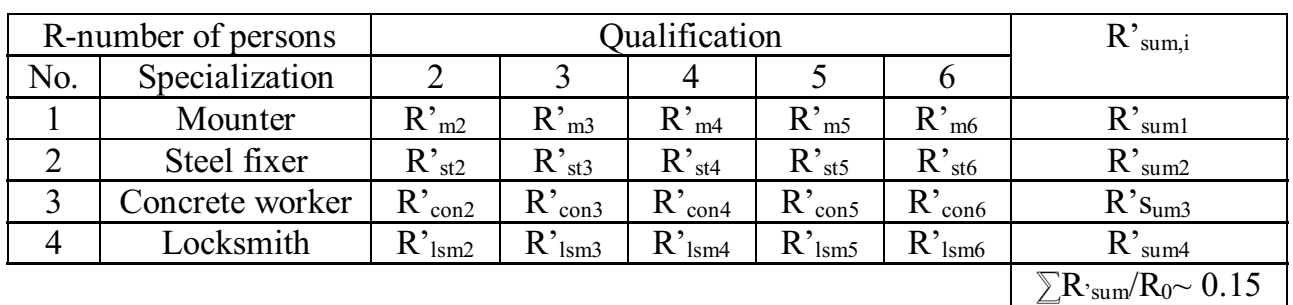

The next step is to describe these objects. The date of the late and early start and ending of construction, which determines its duration, is tied to each object, as well as the total amount of work for a preliminary assessment of the situation.

Table 3. Time intervals of objects.

\begin{tabular}{|c|c|c|c|c|c|c|c|c|}
\hline No. & $\begin{array}{l}\text { Object } \\
\text { name }\end{array}$ & $\begin{array}{l}\text { Early } \\
\text { start }\end{array}$ & $\begin{array}{l}\text { Late } \\
\text { start }\end{array}$ & $\begin{array}{l}\text { Early } \\
\text { ending }\end{array}$ & $\begin{array}{l}\text { Late } \\
\text { ending }\end{array}$ & $\begin{array}{l}\text { Minimum } \\
\text { duration }\end{array}$ & $\begin{array}{l}\text { Maximum } \\
\text { duration }\end{array}$ & $\begin{array}{l}\text { Labor } \\
\text { intensity } \\
\text { of work }\end{array}$ \\
\hline 1 & $\begin{array}{l}\text { Object } \\
1\end{array}$ & $\mathrm{Ti}_{\mathrm{es}}$ & $\mathrm{Ti}_{\mathrm{ls}}$ & $\mathrm{Ti}_{\mathrm{ee}}$ & $\mathrm{Ti}_{\mathrm{le}}$ & \multirow{3}{*}{$t_{\text {mini }}=T i_{\mathrm{ee}}-\mathrm{Ti} i_{\mathrm{s}}$} & \multirow{3}{*}{$\mathrm{t}_{\operatorname{maxi}}=\mathrm{Tile}-\mathrm{Ti}_{\mathrm{es}}$} & $\mathrm{Q}_{\text {itotal }}$ \\
\hline 2 & $\begin{array}{l}\text { Object } \\
2\end{array}$ & $\mathrm{Ti}_{\mathrm{es}}$ & $\mathrm{Ti}_{\mathrm{ls}}$ & $\mathrm{Ti}_{\mathrm{ee}}$ & $\mathrm{Ti}_{\mathrm{le}}$ & & & Q $_{\text {itotal }}$ \\
\hline 3 & $\begin{array}{l}\text { Object } \\
3 \\
\end{array}$ & $\mathrm{Ti}_{\mathrm{es}}$ & $\mathrm{Ti}_{\mathrm{ls}}$ & $\mathrm{Ti}_{\mathrm{ee}}$ & $\mathrm{Ti}_{\mathrm{le}}$ & & & Qitotal \\
\hline
\end{tabular}

Already from these data, it is possible to determine the planned number of workers, i.e. the required capacity of an object $\mathrm{R}_{\text {iplan }}=\mathrm{Q}_{\text {itotal }} /\left(0.5 \cdot\left(\mathrm{t}_{\operatorname{mini}}+\mathrm{t}_{\text {maxi }}\right)\right)$ and check the organization's ability to hand over all the facilities on time. To visualize the data, we use a resource distribution graph that will show the capacity of the organization over time, where the ordinate is found as the sum of the required capacity at a certain moment: $R=\sum R_{\text {iplan }}$

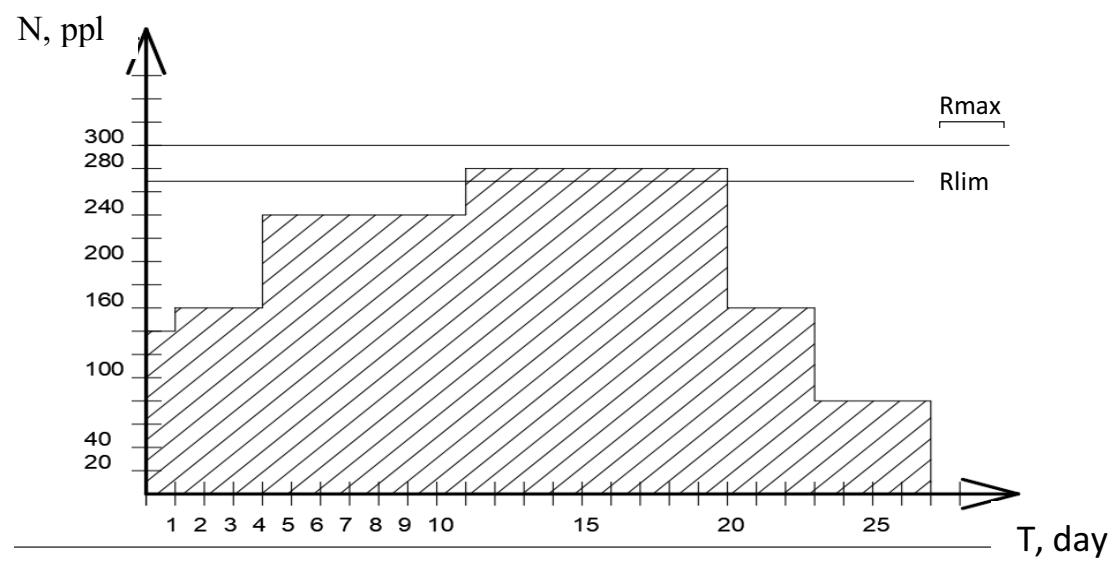

Fig. 2. Capacity of a construction organization. 
If the condition of not exceeding the required resource of the maximum capacity of the organization is met, we perform additional checks. First, we enter detailed information about the planned objects - the required scope of work by specialization.

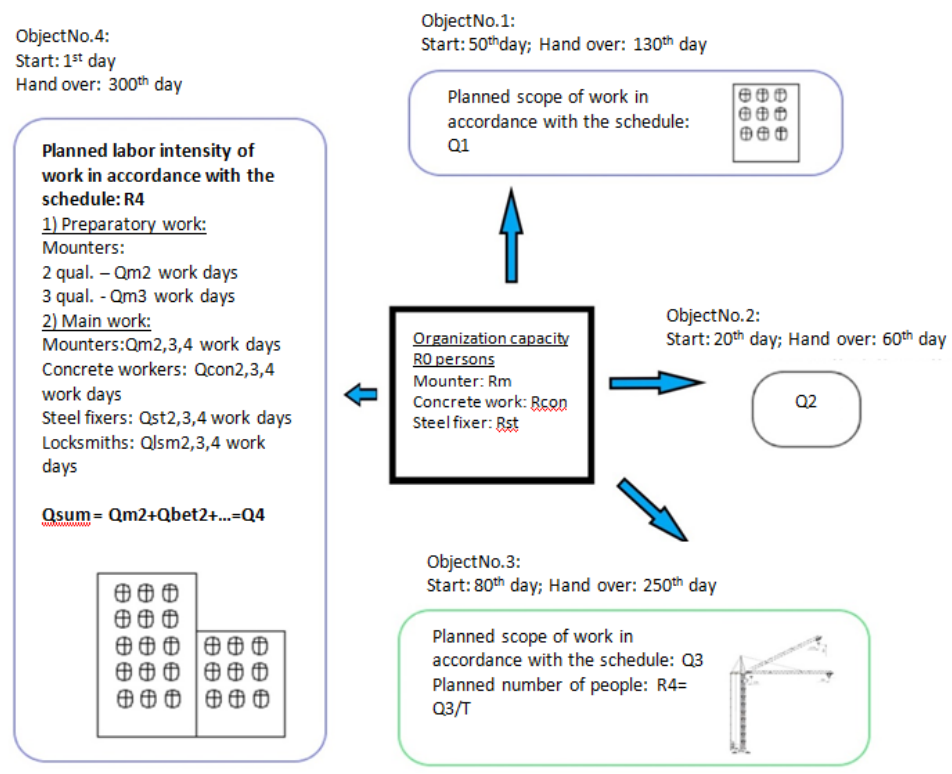

Fig.3. Scheme of planned objects in the current reporting period.

For each object, we build an individual general graph of resource allocation, showing the total number of workers, as well as graphs for the use of individual specializations.

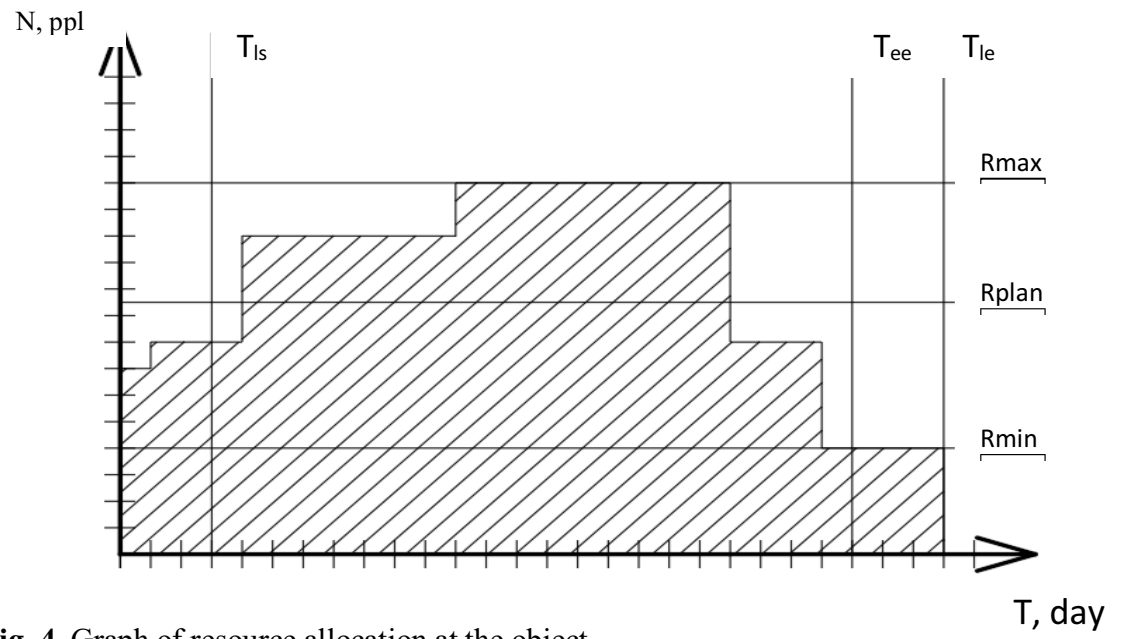

Fig. 4. Graph of resource allocation at the object.

On this graph, $\mathrm{R}_{\max }$ saturation of the scope of work from the condition of rational organization of the workplace for a separate link of performers; $R_{\min }$ - the minimum number of workers at the object. The graphs of the use of individual specializations look the same and carry the following information: the number of specialists involved in time and the total actual scope of work defined as the graph area.

From now on, a person needs to use computer power to enumerate all possible options and evenly distribute the load over objects. For this we use a genetic algorithm. Objective 
function $\mathrm{S}$ of optimizing the workload of production units of the leading flow in general form:

$$
\mathrm{S}=\sum_{i=1}^{n}\left(\mathrm{R}_{\text {fact }}-\mathrm{R}_{\text {plan }}\right) \rightarrow 0
$$

Table 3. An example of the distribution of workers among the objects of the production program for performing monolithic work (excluding the links for the care of concrete structures and intensification of hardening)

\begin{tabular}{|c|c|c|c|c|c|c|c|c|c|}
\hline \multirow[t]{3}{*}{$\begin{array}{c}\text { Program } \\
\text { object }\end{array}$} & \multicolumn{9}{|c|}{$\begin{array}{l}\text { Required number of links rounded up to form a specialized team } \\
\text { (for one tower crane) }\end{array}$} \\
\hline & \multicolumn{3}{|c|}{$\begin{array}{l}1^{\text {st }} \text { option for loading units } \\
\text { ("a") }\end{array}$} & \multicolumn{3}{|c|}{$\begin{array}{l}2^{\text {nd }} \text { option for loading units } \\
\text { ("b") }\end{array}$} & \multicolumn{3}{|c|}{$\begin{array}{l}3^{\text {rd }} \text { option for loading units } \\
\text { ("c") }\end{array}$} \\
\hline & $\begin{array}{c}\text { Reinfor } \\
- \\
\text { cement }\end{array}$ & $\begin{array}{c}\text { Form } \\
- \\
\text { work }\end{array}$ & $\begin{array}{l}\text { Conc- } \\
\text { reting }\end{array}$ & $\begin{array}{c}\text { Reinfor } \\
- \\
\text { cement }\end{array}$ & $\begin{array}{c}\text { Form } \\
- \\
\text { work }\end{array}$ & $\begin{array}{c}\text { Concre- } \\
\text { ting }\end{array}$ & $\begin{array}{c}\text { Reinfor- } \\
\text { cement }\end{array}$ & $\begin{array}{c}\text { Form- } \\
\text { work }\end{array}$ & $\begin{array}{l}\text { Conc- } \\
\text { reting }\end{array}$ \\
\hline Object 1 & $m_{1}^{r}$ & $m_{2}^{r}$ & $m_{3}^{r}$ & $m_{1}^{r}$ & $m_{2}^{r}$ & $m_{3}^{r}$ & $m_{1}^{r}$ & $m_{2}^{r}$ & $m_{3}^{r}$ \\
\hline Object 2 & $m_{1}^{f}$ & $m_{2}^{f}$ & $m_{3}^{f}$ & $m_{1}^{f}$ & $m_{2}^{f}$ & $m_{3}^{f}$ & $m_{1}^{f}$ & $m_{2}^{f}$ & $m_{3}^{f}$ \\
\hline Object 3 & $m_{1}^{c}$ & $\frac{2}{m_{2}^{c}}$ & $\overline{m_{3}^{c}}$ & $m_{1}^{c}$ & $m_{2}^{c}$ & $m_{3}^{c}$ & $m_{1}^{c}$ & $\frac{m_{2}^{c}}{2}$ & $\overline{m_{3}^{c}}$ \\
\hline Object N & 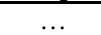 & 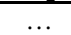 & . & & & & & & \\
\hline
\end{tabular}

Step-by-step implementation of the algorithm.

1. Formation of the so-called pool of distributions of the labor resource of the leading production flow for the given program objects $N=4$, indicating the number of initial variants of distributions (4 variants) $[18,19]$.

2. The initial distribution of labor resources of the leading production flowRij over $i$ program objects according to the $j$-th option, $j \in[1 ; N]$. Substitution of the corresponding arguments into the formulated objective function $F(R i)$. These distributions are formed by a human operator (based on the experience of specialists of a construction organization or specific initial calculations) or by a machine operator of stochastic generation $S$ (randomly) [20,21].

3. Calculation and evaluation of distributions by the value of the calculated fitness function Fit.

3.1. Selection of the distribution Ri1 in the pool, which corresponds to the largest value of the fitness function Fit. This distribution remains unchanged in the formation of the next "generation" of solutions (options for the distribution of labor resources).

3.2. Ordering the distributions in the pool in descending order of the fitness function Fit: Ri1, Ri2, Ri3, Ri4.

4. Crossing $R i 2$ and $R i 3$ by maximizing the concentration of labor resources of production units at the pilotobjects of the program.

5. Mutation Ri4 - adding new solutions according to the principle specified by the operator.

6. Return to step No. 3. 

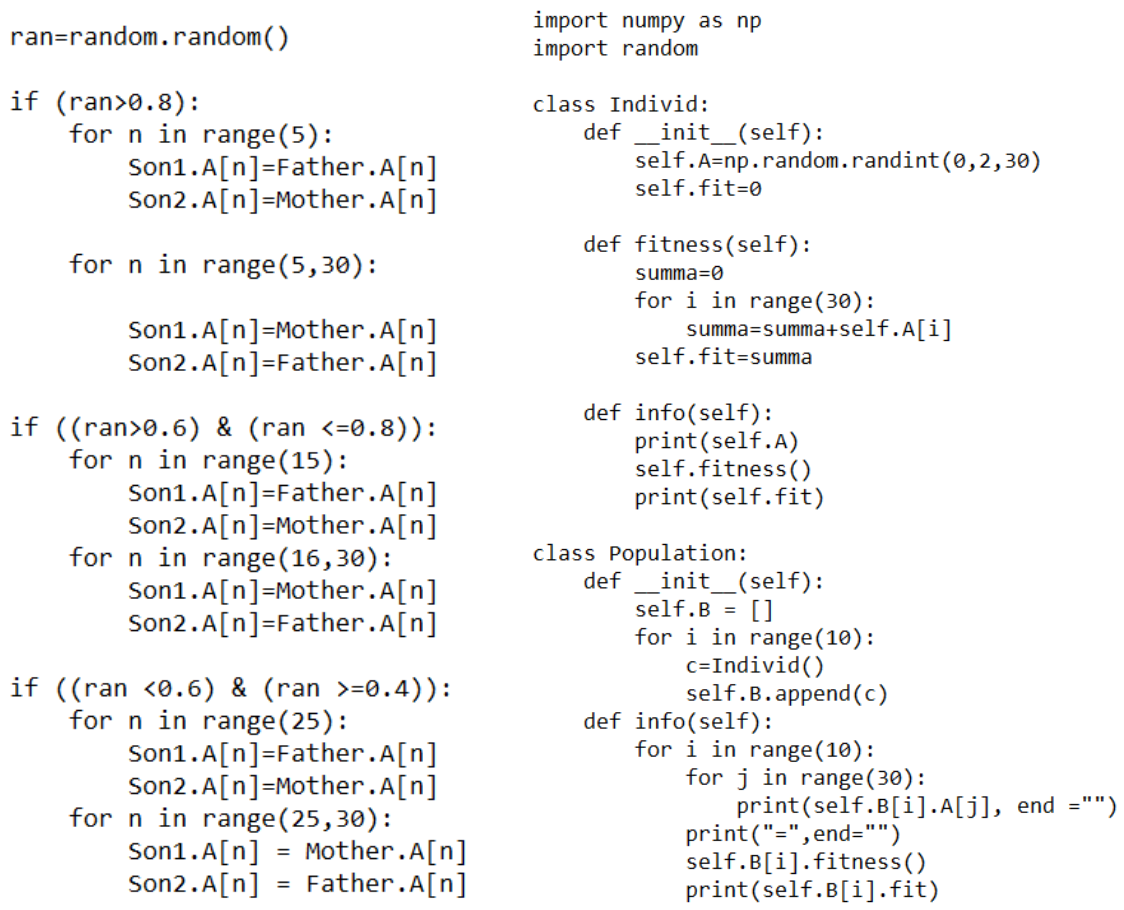

Fig. 5. Part of the genetic algorithm in the program.

\section{Results and discussions}

The developed algorithm made it possible to form an optimal solution for the distribution of workers in the production program according to the following data and steps. At the same time, the formed program was characterized by the execution of construction work on the leading flow within the established directive time, and the revealed fluctuations in the number of workers in the safe corridor of values were leveled out due to the disclosure of internal reserves of technical regulation [22].

Initial data:

1. The capacity of the construction organization is $\mathrm{R}$ (people). The planned number of own labor resources by specializations and qualifications (Rmounter2, Rcarpenter3, Rconcreteworker...). Based on the number of personnel, the recommended reserve required for unplanned work is determined.

2. The number of objects in the current period and their distance from the base of the organization. Distance from the base affects the ability to transfer resources between objects.

3. Specified deadlines for the performance of work under general contracting agreements, according to which the criticality of the object is determined.

4. Planned scope of work: total for each object and for various jobs.

5. Coefficient of combining work for the rational formation of the team.

6. The minimum and maximum planned number of workers on site. Entered by the operator or generated by the program.

Conditions and constraints:

1. The work must be completed on time.

2. The number of resource transfers should be minimal. 
3. The smoothest distribution of workers, objective function $S$ of load optimization $\rightarrow 0$.

4. Number of workers at the object: $R_{\min }<=R<=R_{\max }$.

5. Minimum involvement of subcontractors in case of lack of own capacity.

Algorithm for solving:

1. Input of initial data;

2. Determination of the duration of construction and the planned number of workers at the object;

3. Formation of the ratio of the composition of teams, taking into account the coefficient of combining work and the scope of specialized work;

4. Formation of the initial array of distribution of labor resources using a random number generator or using an operator;

5. Assessment of the variant of resource allocation according to the objective function;

6. Determination of the best option and comparison with other generated options using a genetic algorithm;

7. Data output: best and closest to best option to provide a choice to the operator.

\section{Conclusions}

In connection with the general trend of digitalization and automation of the construction industry, all processes associated with the implementation of a project at any stage are modeled in a common information environment. Thus, in such a single information space, a relationship is also formed between the functional processes of the participants in the construction project. The automation of planning processes for the distribution of labor resources of a construction and installation organization allows integrating algorithms for a targeted enumeration of possible options for the formation of the numerical and qualification composition of teams along the leading flowinto control systems based on the principles of information modeling [24,25]. These algorithms allow rationalizing the use of labor resources relative to the initial capacity of the organization, while optimization by the objective function, taking into account the constraints introduced by the planning operator, provides for an assessment of the effect of actual production conditions at facilities for correct forecasting.

The use of genetic algorithms in the formation of resource graphs and work schedules allows realizing the following advantages of automated planning over manual and unsystematic ones:

1. Reducing the labor costs of the planning operator (department, specialist, manager).

2. Variable organizational and technological design, planning and forecasting.

3. Constant full load of the initial capacity of the construction organization.

4. Concentration of labor resources on target objects.

5. Formation of an array of optimization solutions in accordance with the actual production situation.

\section{References}

1. T.N. Tsai, P.G. Grabovy, V.A. Bolshakov, Organization of construction production. Textbook (ASV, Moscow, 1999).

2. P.P. Oleinik, Fundamentals of organization and management in construction: textbook, 2nd edition, rev. (ASV, Moscow, 2016).

3. V.V. Buzyrev, E.V. Gusev, I.P. Savelyeva, Planning in a construction company 
4. V.V. Buzyrev, A.P. Suvorova, I.V. Fedoseev, N.V. Chepachenko, Construction economics: textbook/2nd edition. (Academy, Moscow, 2007).

5. V.Ya. Mishchenko, D.I. Emelyanov, A.A. Tikhonenko, Substantiation of the expediency of using genetic algorithms to optimize resource allocation in the scheduling of construction Industrial and civil engineering, 10 71-73 (2013).

6. P. Oleinik, A. Yurgaytis, MATEC Web of Conferences 11700130 (2017). https://doi.org/10.1051/matecconf/201711700130

7. D. Topchiy, A. Shatrova, A. Yurgaytis, MATEC Web of Conferences 19305032 (2018). https://doi.org/10.1051/matecconf/201819305032

8. P. Oleinik, A. Yurgaytis, MATEC Web of Conferences 19305010 (2018). https://doi.org/10.1051/matecconf/201819305010

9. P. Oleinik, A. Yurgaytis, G. Voronina, A. Makarenko, MATEC Web of Conferences 25105037 (2018). https://doi.org/10.1051/matecconf/201825105037

10. P. Oleinik, A. Yurgaytis, MATEC Web of Conferences 26507024 (2019). https://doi.org/10.1051/matecconf/201926507024

11. V.Chulkov, A. Yurgaytis, E3S Web of Conferences 16410032 (2020). https://doi.org/10.1051/e3sconf /202016410032

12. P. Oleinik, A. Yurgaytis, E3S Web of Conferences 17511016 (2020). https://doi.org/10.1051/e3sconf/202017511016

13. A. Tzarenko, A. Yurgaytis, IOP Conf. Series: Materials Science and Engineering 753032072 (2020). doi:10.1088/1757-899X/753/3/032072

14. P. Oleinik, A. Yurgaytis, IOP Conf. Series: Materials Science and Engineering $\mathbf{7 5 3}$ 032077 (2020). doi:10.1088/1757-899X/753/3/032077

15. M. Rogalska, W. Bozejko, Z. Hejducki, Automation in Construction 18 24-31 (2008). doi:10.1016/j.autcon.2008.04.002

16. W. Bozejko, Z. Hejducki, M. Uchroński, M. Wodecki, Journal of Civil Engineering and Management 20 (2014). DOI: 10.3846/13923730.2014.906496

17. W. Bozejko, Z. Hejducki, M. Wodecki, Journal of Civil Engineering and Management 18 (5) 621-630 (2012).

18. M. Rogalska, W. Bozejko, Z. Hejducki, M. Wodecki, Development of time couplings method using evolutionary algorithms, ISARC 2008 - Proceedings from the 25th International Symposium on Automation and Robotics in Construction (2008)

19. M. Uchroński, W. Bożejko, Z. Krajewski, M. Tykierko, M. Wodecki, International Conference on Dependability and Complex Systems 1 504-514 (2018)

20. W. Bożejko, A. Gnatowski, J. Pempera, M. Wodecki, Computers \& Industrial Engineering 113 512-524 (2017).

21. M. Walczyński, W. Bożejko, D. Skorupka, AIP Conference Proceedings 1863 (1) 230014 (2017).

22. W. Bożejko, J. Pempera, M. Wodecki, Archives of Control Sciences 27 (2) 169-181 (2017).

23. A. Yurgaytis, K. Kamolov, Modern methods of organization and construction management, St. Petersburg State University of Architecture and Civil Engineering, St. Petersburg 224 (2020). ISBN 978-5-9227 
24. A.O. Khubaev, T.H. Bidov, V.A. Nesterova, A.A. Bzhenikov, IOP Conf. Series: Materials Science and Engineering 365032005 (2018). DOI:10.1088/1757899X/365/3/032005/

25. A.O. Khubaev, T.H. Bidov, A. Rybakova, MATEC Web of Conferences 19604071 (2018). DOI:10.1051/matecconf/201819604071/ 